\title{
Using Simulated Parent-Teacher Talks to Assess and Improve Prospective Teachers' Counseling Competence
}

\author{
Mara Gerich ${ }^{1}$ \& Bernhard Schmitz ${ }^{1}$ \\ ${ }^{1}$ Institute of Psychology, Technische Universität Darmstadt, Germany \\ Correspondence: Mara Gerich, Institute of Psychology, Technische Universität Darmstadt, Germany. \\ Alexanderstraße 10, 64283 Darmstadt, Germany. Tel: 49-6151-162-4071. E-mail:
} gerich@psychologie.tu-darmstadt.de

Received: February 22, 2016

Accepted: March 11, $2016 \quad$ Online Published: April 4, 2016

doi:10.5539/jel.v5n2p285

URL: http://dx.doi.org/10.5539/jel.v5n2p285

\begin{abstract}
In research on parental involvement and teacher professionalization, counseling parents on the support of their children's learning processes is considered to be an increasingly important competence area of teachers. However, to date little research has been conducted on the development of appropriate approaches to the assessment of teachers' counseling competence. The current study describes the validation of a behavior-based instrument for the assessment of teachers' counseling competence including counseling talk simulations with standardized parents as well as the examination of its suitability as an intervention for the improvement of participants' counseling competence. The validation was carried out within the framework of a longitudinal quasi-experimental study with 51 prospective teachers. Multivariate repeated measures MANOVAs revealed the suitability of the counseling talk simulations both as an assessment instrument and an intervention. Results provide numerous implications for teacher preparation and continuing education, for example, the use of the counseling talk simulations as a didactical tool within the framework of teacher training programs.
\end{abstract}

Keywords: behavior-based competence assessment, counseling talk simulations, counseling competence, intervention, teacher education

\section{Introduction}

Counseling students and their parents is considered to be an increasingly important task for teachers (Guli, 2005; Valli \& Rennert-Ariev, 2000). Consequently, it has even been specified as a key aspect in recent concepts of teachers' professional competences (e.g., Baumert \& Kunter, 2006) as well as world-wide government recommendations and standards for teacher education (e.g., National Commission on Teaching and America's Future, 1997; Standing Conference of the Ministers of Education and Cultural Affairs of the States in the Federal Republic of Germany, 2004). In particular, counseling parents concerning the support of their children's learning activities plays an increasingly important role (Whiston, Tai, Rahardja, \& Eder, 2011), as research on parental involvement has frequently demonstrated its beneficial effects on students' academic development as well as their social, emotional, and behavioral adjustment (Cox, 2005; Hill \& Tyson, 2009; Pomerantz, Moorman, \& Litwack, 2007). Especially home-based involvement practices, such as providing assistance with homework, enhancing motivation, and structuring time for homework and leisure, have been shown to improve academic achievement (Fan \& Chen, 2001; Henderson \& Mapp, 2002). Consequently, parents increasingly request guidance from teachers concerning the support of their children in homework and learning activities (Hoover-Dempsey, Walker, Jones, \& Reed, 2002). Consequently, in order to meet these high demands and capitalize on the full potential of involving parents in their children's learning processes, teachers have to possess essential counseling competences.

\subsection{Assessment of Teachers' Counseling Competence}

Although the current state of research clearly emphasizes the prominent role of teachers' counseling competence in parent-teacher talks in the development of high-quality educational processes, there has been little research on this important teacher competence. Approaches to the measurement of teachers' counseling competence in parent-teacher talks, in particular, are still rare. To date, there are only a few instruments for its standardized assessment, which are primarily based on self-reports. For example, Hertel (2009) developed a self-assessment questionnaire for the measurement of teachers' counseling competence including the scales personal resources, 
social cooperation competence, counseling skills and pedagogical knowledge, process competence, and coping. However, instead of capturing a person's real competences in specific situations, self-reports are more likely to record an individual's general self-concept (Spencer \& Spencer, 1993) or the importance assigned to a specific behavior (Constantine \& Ladany, 2000). On this account, approaches to the more objective and contextual assessment of teachers' counseling competence in parent-teacher talks are necessary.

To this, Bruder (2011) developed and validated a Situational Judgement Test (SJT) for the assessment of teachers' counseling competence in parent-teacher talks. As SJTs have been shown to have substantial criterion-related validities for the criterion of job performance (McDaniel, Morgeson, Finnegan, Campion, \& Braverman, 2001), the author considered the SJT approach to be a promising method for measuring teachers' counseling competence in a behavior-based manner. The author developed 13 items measuring the scales counseling skills, diagnostic and pedagogical knowledge, collaboration and perspective taking, and coping. Each of the 13 items describes a short, realistic parent counseling situation in which a specific behavior is requested followed by four multiple-choice answer options presenting a range of possible activities. The participant is asked to choose the best and worst possible activities. In a subsequent study, Bruder, Keller, Klug, and Schmitz (2011) additionally established a short test form of the SJT including 6 of the original 13 items.

\subsection{Scenario Test for the Assessment of Teachers' Counseling Competence}

To date, one of the best validated instruments for the assessment of teachers' counseling competence in parent-teacher talks on the support of students' educational processes is a scenario test established by Bruder (2011) and Gerich, Bruder, Hertel, Trittel, and Schmitz (2015). The scenario test is based on the model of teachers' counseling competence in parent-teacher talks on the support of students' learning processes (in the following, we use the abbreviated term "counseling competence") by Gerich et al. (2015, see Figure 1). This four-dimensional model was developed on the basis of literature on general counseling competence, counseling in schools, parent counseling, and counseling on learning strategies (e.g., Guli, 2005; McLeod, 2003; Sheridan, Kratochwill, \& Bergan, 1996) as well as preliminary approaches to modeling teachers' counseling competence for the subsample of higher track secondary school teachers (Bruder, 2011; Hertel, 2009). The proposed model structure was empirically validated conducting structural equation modeling on the basis of 357 primary and secondary school teachers' data. The model includes the most important skills and abilities that a teacher should possess in the context of counseling parents in how to support their children's educational progress: (1) communication skills, containing general counseling practices such as "active listening", "paraphrasing", and "structuring" the talk; (2) diagnostic skills, including aspects necessary to analyze existing problems and identify potential causes such as "problem definition", "search for possible causes", and "perspective taking"; (3) problem-solving skills, comprising aspects necessary to develop and initiate appropriate and customized solutions for learning difficulties such as "application of learning strategies", "goal orientation", "solution and resource orientation", and "cooperative actions"; and (4) coping skills, including strategies for "coping with criticism" and "dealing with difficult situations" in the course of the counseling talk. In addition to these four dimensions, the authors identified several specific variables that are positively related to the level of teachers' counseling competence: knowledge of counseling and learning strategies, professional self-concept as a counselor, and counseling experience (in the following, these terms are used interchangeably with the abbreviations "knowledge", "professional self-concept", and "experience").

The scenario test was developed for the assessment of teachers' counseling competence both overall as well as subdivided into the four competence dimensions. As scenario tests have been shown to be appropriate to measure competences in a standardized and economical manner that is context specific and closely related to behavior (Hedlund, Witt, Nebel, Ashford, \& Sternberg, 2006), they have often been used in research on professional competences, even in the field of teacher competences (e.g., Klug, Bruder, Kelava, Spiel, \& Schmitz, 2013). The scenario test for the assessment of teachers' counseling competence contains a case study of a student with learning difficulties whose mother is seeking advice and thus requests a counseling talk. Participants are requested to respond to 12 open-ended questions referring to the information given in the case study. These questions represent the 12 content variables of the four dimensions of teachers' counseling competence (e.g., "What information would you collect prior to and during the talk with Kristina's mother in order to find possible solutions to implement after the talk?" for the variable search for possible causes). In the evaluation of participants' responses, the qualitative statements are converted into quantitative scores by means of a detailed rating system (for a comprehensive description of the scenario test, its development and validation, see Bruder (2011) and Gerich et al. (2015)). 


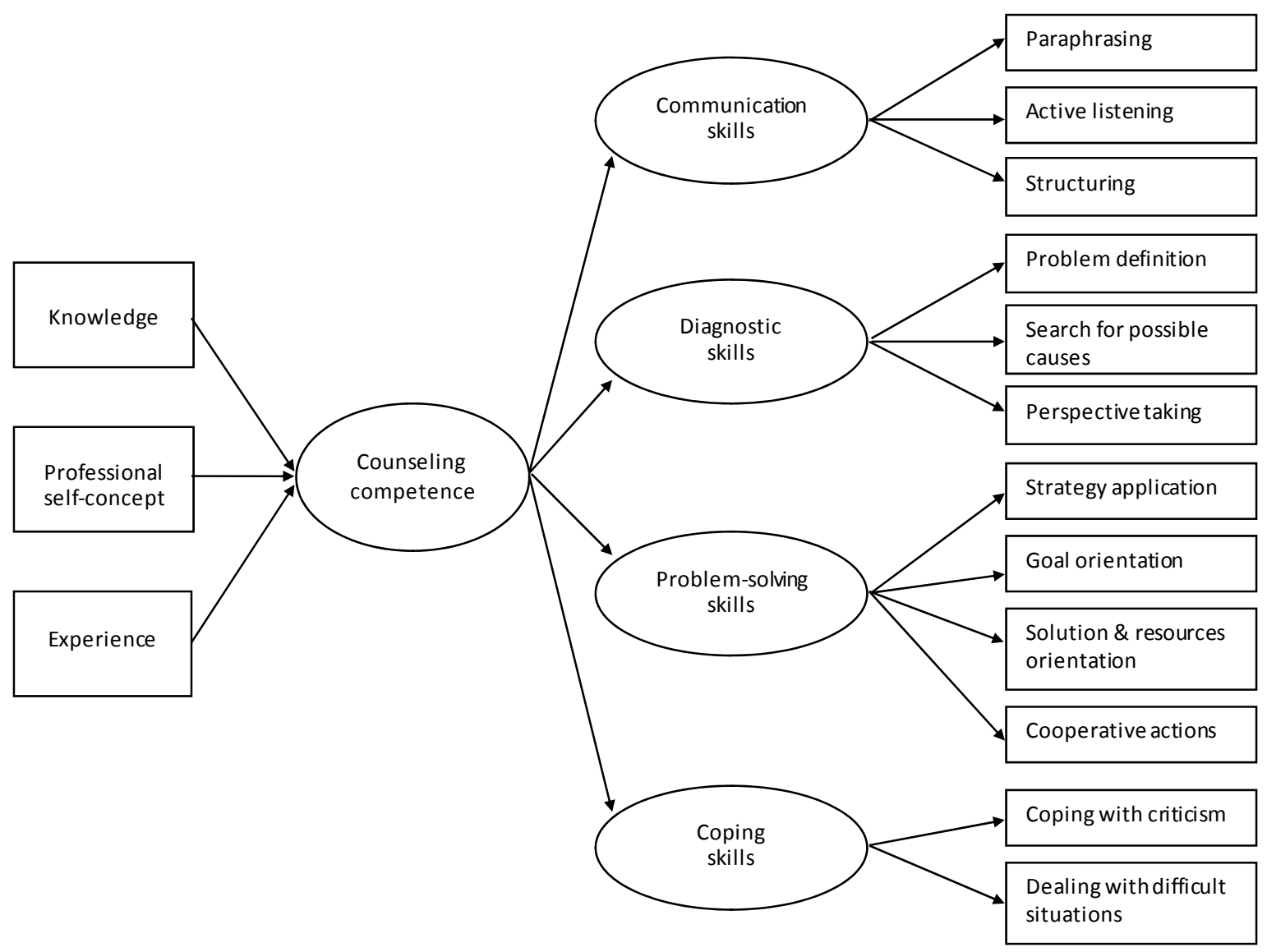

Figure 1. Model of teachers' counseling competence (Gerich et al., 2015)

\subsection{Behavior-Based Instruments for the Assessment of Teachers' Counseling Competence}

In the studies by Bruder (2011) and Gerich et al. (2015), the scenario test has been shown to be an objective and economic strategy for the itemized measurement of teachers' counseling competence. Nevertheless, behavior-based instruments for the assessment of teachers' counseling competence, for example, direct performance observation in concrete and realistic application situations (Kane, 1992), have yet to be developed.

In this context, a promising alternative is the performance observation in videotaped simulated parent-teacher talks involving role-playings with standardized parents. This approach appears to be suitable, as the level of counseling competence measured in role-play situations has already been shown to largely correspond to the level of counseling competence demonstrated in real counseling talks in a study with counseling students (Gallagher \& Hargie, 1989). Moreover, because video recording has been shown to be an appropriate and valid strategy for the simultaneous assessment of multifaceted pedagogical skills, especially in the field of counseling (e.g., Admiraal, Hoeksma, van de Kamp, \& van Duin, 2011), this method also appears appropriate for measuring teachers' counseling competence in simulated parent-teacher talks on the support of students' learning processes.

One of the first approaches of applying simulated parent-teacher talks in the field of teacher education was established by Dotger and colleagues (Dotger, Dotger, \& Maher, 2010; Dotger, Harris, \& Hansel, 2008). In the Simulated Interaction Model (SIM), prospective teachers participate in a series of one-on-one interactions with standardized parents within the framework of a teacher training course. These standardized parents are carefully trained actors who are scripted to present specific statements, questions, or concerns-known as "verbal triggers"-during the parent-teacher talk simulations in accordance with a carefully designed case profile. In contrast, the teacher candidate taking part in the simulation is given an "appropriate" amount of background knowledge regarding the hypothetical student in terms of a general academic profile, but is not scripted in any way concerning his or her behavior during the interaction with the standardized parent. The simulated parent-teacher talks are videotaped in order to subsequently provide participants extensive feedback on their performance during the simulations. Furthermore, participants conduct detailed self-evaluations, supported by 
their careful review of the video recordings of their simulated interactions as well as individual and whole-group debriefing sessions.

In the first instance, the SIM was developed as an intervention for enhancing prospective teachers' communication skills in parent-teacher talks. In a subsequent study, Walker and Dotger (2012) utilized the videotaped simulations to measure prospective teachers' readiness for parent-teacher interactions. In this context, the videotaped simulations functioned as models of effective and less-effective teacher-parent communication. After reading the related background information of the hypothetical student and before viewing the respective videotaped simulation, participants were asked what they would do to make the talk successful, what strategies they would use, and what else they would like to know, if they were the teacher in this situation. Subsequently, candidates watched two videos that involved two different teacher models interacting with the same standardized parent and evaluated the teachers' performance along several dimensions derived from expert opinion. Moreover, candidates chose which of the two models performed better. Although Walker and Dotger (2012) used simulated parent-teacher talks, participants' conversation competences were not assessed via participants' own behavior in the specific situation. Instead, they were measured by means of participants' theoretical descriptions of how they would act in the given situation as well as their rating of the demonstrated conversational skills of specified teacher models.

A first attempt to measure prospective teachers' own behavior in simulated parent-teacher talks was introduced by Wiesbeck, Bauer, Gartmeier, and Prenzel (2013). By means of videotaped simulations with standardized parents, the authors aimed to assess prospective teachers' communicative competence in parent-teacher talks-a construct related to teachers' counseling competence. For the evaluation of the videotaped conversations, the authors applied a detailed rating system based on the study's underlying Munich model of teachers' communicative competence in parent-teacher talks (Gartmeier, Bauer, Fischer, Karsten, \& Prenzel, 2011) comprising the three facets interpersonal relationship, problem-solving, and structuring the conversation.

\subsection{Purpose of the Current Study}

Even though Dotger et al. $(2008,2010)$ as well as Wiesbeck et al. (2013) already developed behavior-based simulation approaches to the assessment of teachers' communication skills, there are still no instruments for the behavior-based assessment of teachers' counseling competence in parent-teacher talks on the support of students' learning processes. Therefore, the superior aim of the current study was to develop and validate a behavior-based instrument based on the four-dimensional model of teachers' counseling competence (Gerich et al., 2015) involving counseling talk simulations with standardized parents in the same style of the SIM approach by Dotger et al. $(2008,2010)$ as well as the assessment approach by Wiesbeck et al. (2013). Here, in order to particularly utilize the instrument for the evaluation of specific teacher training programs on counseling, we strove for an instrument for the longitudinal assessment of changes in teachers' counseling competence due to specific interventions. For validation purposes, we aspired to compare longitudinal data acquired by means of the counseling talk simulations with longitudinal data gathered by means of the already established scenario test by Bruder (2011) and Gerich et al. (2015) described above.

In addition to its utilization as a measurement instrument, we aimed to examine whether participation in the counseling talk simulations could serve as an intervention for the improvement of prospective teachers' counseling competence within the context of teacher preparation. In the studies carried out by Dotger et al. $(2008,2010)$, participation in simulated parent-teacher talks provided prospective teachers an opportunity to practice their abilities to effectively partner with parents and, subsequently, led to an enhancement of participants' communication skills. The beneficial effects of practicing professional skills in concrete case-based application situations on the development of competences have also been demonstrated in other studies on teacher education (e.g., Grossmann, 2005). By means of active learning, learners are given the possibility to apply their theoretical knowledge in practical, realistic situations in order to acquire practical competences, gain experience, and facilitate the transfer of training content to future professional routines. Based on this, active learning by the use of videotaped simulated parent-teacher talks appears to be a promising opportunity even in the context of enhancing prospective teachers' counseling competence in parent-teacher talks on the support of students' learning processes.

In summary, the present study addressed the following hypotheses:

1) The counseling talk simulations serve as an appropriate instrument for the assessment of changes in prospective teachers' counseling competence due to specific interventions. It is expected that intervention effects on teachers' counseling competence measured by means of the counseling talk simulations are consistent with measurements determined by means of the scenario test (Bruder, 2011; Gerich et al., 2015). 
2) The counseling talk simulations serve as an effective intervention for the improvement of prospective teachers' counseling competence. It is expected that participation in the counseling talk simulations leads to an increase in teachers' counseling competence as well as the related variables (knowledge of counseling and learning strategies, professional self-concept as a counselor, counseling experience) identified by Gerich et al. (2015).

\section{Method}

\subsection{Sample}

The study took place at a university in the German federal state of Hesse within the scope of an optional training module on educational psychology for prospective teachers. The total sample consisted of 51 prospective teachers $(66.7 \%$ women) ranging in age from 21 to 34 years $(M=23.06, S D=2.20)$ who were currently in semester 2 through 10 of their studies $(M=6.65, S D=1.66) .23(45.1 \%)$ prospective teachers studied mathematics, 25 (49.0\%) natural sciences, 8 (15.7\%) languages, $20(39.2 \%)$ social sciences, and $12(23.5 \%)$ art, music, and/or physical education. None of the participants had previously gathered initial experiences in counseling parents; six students $(11.8 \%)$ had previously participated in courses on counseling.

\subsection{Procedure}

The longitudinal study was carried out within the framework of a quasi-experimental study on the evaluation of a training program on counseling competence for prospective teachers (for a detailed description of the training program and its evaluation, see Gerich, Trittel, \& Schmitz, under review). In order to examine our research questions, we observed two experimental groups. The design was quasi-experimental, because the participants could not be randomly assigned to the intervention groups. Instead, the groups established themselves by the students' optional enrollment in one of two training courses. However, participants did not know about the different experimental conditions. The experimental groups did not significantly differ with regard to their demographic data.

Both experimental groups (experimental group 1 [EG1]: $N=25$; experimental group 2 [EG2]: $N=26$ ) participated in the training program as separate groups. The training program consisted of nine weekly sessions of 100 minutes each. Prior to and after receiving the training intervention, participants completed an extensive paper-pencil survey (paper-pencil pretest and posttest) for the assessment of participants' counseling competence, knowledge, professional-self concept, and experience, based on the four-dimensional model of teachers' counseling competence (Gerich et al., 2015). Experimental group 1 additionally participated in the simulated parent-teacher counseling talks at two different points in time (simulation pretest and posttest). The simulation pretest took place one week after the paper-pencil pretest and the simulation posttest was carried out one week before the paper-pencil posttest.

\subsection{Measures}

\subsubsection{Paper-Pencil Tests}

Within the framework of the paper-pencil pretest and posttest, participants' counseling competence was measured by means of the aforementioned scenario test established by Bruder (2011) and Gerich et al. (2015) (see section Introduction). Participants' responses to the 12 open-ended questions following the case scenario-which represent the content variables of the four-dimensional model of teachers' counseling competence (Gerich et al., 2015)-were converted into scores from 0 to 2 for each item using a detailed standardized rating system. The rating system includes an extensive set of potential answers to each question as well as detailed specifications on the respective scores to be awarded. The coding was carried out by well-trained raters with sufficient content knowledge on parent counseling and learning strategies. In order to test the objectivity of the rating system, and thus its robustness against any personal biases or predispositions of the raters, inter-rater reliabilities for each question were calculated in a previous study (Gerich et al., 2015), resulting in satisfactory intra-class-correlations (ICC; McGraw \& Wong, 1996) between ICC $=.72$ and ICC $=1.00$.

Moreover, within the paper-pencil pretest and posttest, we measured the three variables, which are positively related to the level of teachers' counseling competence (Gerich et al., 2015): knowledge of counseling and learning strategies, professional self-concept as a counselor, and counseling experience. Participants' knowledge of counseling and learning strategies was measured by means of a multiple-choice test composed of nine closed-ended questions with four possible answers each. The knowledge test includes four multiple-choice items on professional knowledge of counseling (e.g., "What are the advantages of the active listening technique in a counseling talk?") and five items on knowledge of learning strategies (e.g., "Which possibilities does a student have to motivate himself/herself while studying?"). Participants are asked to choose the best answer or answers 
(the latter in cases where multiple answers were allowed, which is clearly marked next to the respective item). Participants' responses to all items are coded as either correct or incorrect. Item difficulties determined in a previous study ranged between .35 and .89 and thus fell within an acceptable range for inter-correlated items (Ramsey \& Reynolds, 2000). The examination of scale reliability in a previous study revealed an acceptable Cronbach's alpha of $\alpha=.63$.

The self-assessment questionnaire on professional self-concept as a counselor and counseling experience consists of 23 closed-ended items. Participants are asked to respond to each item on a six-point rating scale ranging from 1 (I completely disagree) to 6 (I completely agree). The scale professional self-concept includes 15 items concerning prospective teachers' attitudes towards counseling, motivation for counseling, self-efficacy in counseling, and sense of self as a counselor (e.g., "I believe that, as a teacher, part of my job is to counsel parents."). The experience scale consists of 8 items on prospective teachers' previous education and experiences in counseling as well as reflection on one's own counseling behavior in previous counseling talks (e.g., "After finishing a counseling talk, I think about whether I am satisfied with my performance as a counselor."). The examination of scale reliability in a previous study indicated satisfactory Cronbach's alphas of $\alpha=.77$ for professional self-concept as a counselor and $\alpha=.86$ for counseling experience.

\subsubsection{Counseling Talk Simulations}

The development of the materials for the simulated parent-teacher counseling talks was also based on the model of teachers' counseling competence (Gerich et al., 2015). We constructed two specific case examples of hypothetical students (Manuel for the simulation pretest and Marie for the simulation posttest) with certain difficulties in learning that are supposedly causing a decline in their achievement, which formed the basis for the preparation of the written instructional materials for the participating teacher as well as the actor portraying the simulated parent.

Similar to the scenario test, the materials for the participating teacher each include a detailed profile of the respective student providing general demographics (name, age, grade level), information on the student's social and personal characteristics, and, most importantly, current academic and behavioral conspicuities. Moreover, the profile outlines certain educational initiatives already taken by the teacher, previous communication with the student's parents, and the occasion of the upcoming teacher-initiated parent-teacher talk with the student's mother. The profile does not in any way specify exactly the teacher's actions, decisions, or verbalizations within the simulated counseling talk. The instruction materials additionally include the request of the participants to carefully read the profile, empathize with the teacher's character, and prepare for the upcoming counseling talk. In addition, participants are informed about the time limit of 15 minutes for the counseling talk.

For the role of the hypothetical students' parents, we also constructed detailed instructional materials that allowed for the careful preparatory training of the actors portraying the simulated parents within the counseling talk simulations. For both of the developed cases, those materials each include a detailed profile of the respective hypothetical student. In contrast to the student's profile presented to the participating teachers, the profile given to the simulated parents provides home-based background context as well as a detailed interaction protocol for the simulated parent-teacher talk. By means of this interaction protocol, the standardized parents are instructed to present exact predetermined questions, information, and statements-according to the verbal triggers in the studies by Dotger et al. $(2008,2010)$-at specified times during the course of the parent-teacher talk. For instance, after the teacher addresses the hypothetical student's unsatisfactory homework completion, the simulated parent is instructed to signalize a certain helplessness concerning the corresponding causes by stating "I am completely at a loss as to what could be the problem with his/her homework completion". This statement is intended to examine whether the participating teacher is able to take into account potential causes for students' learning difficulties from different contexts (e.g., insufficient learning strategies, motivational or emotional problems) and ask appropriate and purposeful questions. At a later stage in the counseling talk, the simulated parent is instructed to suddenly criticize the teachers' professional practice by stating "I have had a look at your latest class test and it is my opinion that the exam questions were much too difficult", in order to examine the teacher's ability to professionally deal with parental criticism. Even though the standardized parents are instructed to closely adhere to the interaction protocol during the counseling talk simulations, they must also adapt to the individual conversational actions of the respective participating teacher. Thus, the training of the simulated parents particularly focused on additional contingency responses that they may employ during the simulation depending of the specific actions of the teacher. Excerpts of the instructional materials for the teacher and simulated parent concerning the case example Manuel are shown in Table 1. 
Table 1. Excerpts of the instructional materials for the teacher and the standardized parent concerning the case example Manuel

\section{Materials for the teacher}

\section{Instruction}

Your task: In a role-play counseling situation, you will conduct a counseling talk with a student's parent. In order to successfully complete the task, it is important that you can identify with your role in the counseling talk. Please take your time reading the following scenario description. In the role-play situation, act just as you would in a real counseling talk with a parent. The role of the parent will be played by a trained role-player using a standardized script. You now have 10 minutes to prepare yourself for the counseling talk. Feel free to make notes to help you during the counseling talk. The role-play will last about 15 minutes and will be videotaped.

\section{Scenario}

You teach seventh grade math at a higher track secondary school. Today you have a counseling talk planned with the mother of 12 year old Manuel. Since the beginning of the school year, you have noticed that Manuel's math grades are continually getting worse. He seldom does his math homework. When he does, it is often incomplete and sloppy. Because you often teach math during the first period of the day, you have noticed that Manuel is often late to school. Otherwise, Manuel is a rather quiet and nice student. You don't believe that he has any cognitive problems; and he seems to understand what you teach in class. During independent work times, Manuel is able to concentrate on his work. He also has good social ties to his peers. Based on conversations with other students, you know that he is interested in movies, computer games, and soccer. You have never met Manuel's parents, since they have never attended parent-teacher conferences. Manuel's mother cancelled an appointment that you had with her two weeks ago because she did not have time to attend. You asked his mother to participate in a counseling talk with you so that you can obtain an impression of Manuel's learning and homework situation at home. You also want to work with her to find ways to improve Manuel's learning and homework habits.

\section{Materials for the standardized parent}

\section{Scenario}

You are the mother of 12 year old Manuel. He is in the seventh grade at a higher track secondary school. You have always had the impression that he is a relatively good student. However, lately his grades have not been as good. You don't know why that is, since he is an intelligent child. He is constantly demonstrating his ability to quickly learn new things when he plays computer games on the weekends with his friends and always ends up the winner. He also often watches sophisticated movies and really enjoys thinking up new strategies for his soccer team. You promised him that you would finally make it to one of his games to cheer him on, but for the last year you have been working so much that you are usually grateful just to make it home in time for a family dinner. Your partner is also often away on business, so you are very proud that Manuel is such an independent child. In the mornings, Manuel has to get ready for school on his own, since you leave the house before he does. Still, you always take the time to make breakfast for him and pack his lunch, even though you think he is too old for that. However, you do regret the fact that you are so busy at work. For example, you would really like to be able to attend a parent-teacher conference so that you can talk with Manuel's teachers and other parents. Two weeks ago you even had to cancel an appointment with Manuel's math teacher because you just didn't have the time to go. Because of that, you are really glad that his teacher has made another appointment with you. You are truly interested in learning about how Manuel behaves at school and what type of student he is. Unfortunately, you don't have the opportunity at home to see how and when he studies and does his homework; and there must be some reason why his grades have gone down... So now you are on your way to the appointment with Manuel's math teacher and are really curious to hear what he/she has to say!

\section{Examples of the predetermined questions, information, and statements}

- After Manuel's problems have been mentioned, ask at some point during the talk what you could do to improve Manuel's performance (if the teacher does not mention this without you asking): "What can we do to help Manuel do better again at school?"

- After the teacher has suggested possible interventions, ask him/her to describe them in detail and ask what exactly you can do as a parent (if the teacher does not mention this without you asking): "Unfortunately, I don't know anything about this method. Can you tell me more about it, especially what exactly I should do?"

- Express critique regarding the teacher's ability to control the class: "Manuel told me that he can't concentrate in class because it is often so loud. So it's not surprising that he isn't performing up to his usual standard. I'm 
starting to think that you don't have your class under control. After all, it's your job to make sure that the students can concentrate on their work!"

The simulations took place in a conference room of the research institution equipped with a table, two chairs, and a video camera. Each simulation began with a preparation phase in which the written case profile of the hypothetical student as well as additional written instructions were presented to the participants. Participants were given ten minutes to read the profile, prepare for the upcoming parent-teacher talk, and ask potential comprehension questions to the test administrator. The preparation phase was followed by the actual counseling talk phase. The video camera was activated, the simulated parent entered the room, and the conversation took place. After the teacher finished the talk, the simulated parent left the room and the video camera was switched off. In the case that the teacher did not bring the counseling talk to an end after a maximum of 15 minutes, the simulated parent terminated the conversation.

To analyze the participants' professional performance during the counseling talk simulations, we developed a detailed standardized rating system also based on the model of teachers' counseling competence (Gerich et al., 2015). By means of this rating system, participants' qualitative statements were converted into quantitative scores from 0 to 2 for each of the competence aspects outlined in the model (except perspective taking, as this aspect could not be adequately observed).

With reference to the evaluation system of the already well-established scenario test for the assessment of teachers' counseling competence (Bruder, 2011; Gerich et al., 2015), we defined precise encoding rules specifying which criteria need to be fulfilled to achieve one or two points as well as appropriate verbalization examples for the teacher. The coding was carried out by well-trained raters with sufficient content knowledge on parent counseling and learning strategies. Excerpts of the rating system are displayed in Table 2.

To verify the content validity of the applied case examples, we carried out an expert survey among a sample of 41 practicing teachers, as expert opinion is considered to be a standard method of establishing content validity (Carmines \& Zeller, 1991). The sample consisted of 25 (61\%) female and 16 (39\%) male teachers ranging in age from 30 to 60 years $(M=42.05, S D=11.00)$, with $M=12.76(S D=9.55)$ years of teaching experience. The respondents were asked to conscientiously read the two case profiles of the hypothetical students and, for each case, answer two questions on a six-point rating scale ranging from 1 (I completely disagree) to 6 (I completely agree): (1) "As a whole, I judge the depicted case example to be realistic"; (2) "The depicted case example describes a typical parent-teacher talk situation with a focus on learning guidance". Results indicated that the experts viewed the case examples to be realistic (Manuel: $M=5.17, S D=.80 ;$ Marie: $M=4.63, S D=1.14$ ) and typical examples of parent-teacher talk situations with a focus on learning guidance (Manuel: $M=5.02, S D=$ 1.04; Marie: $M=4.53, S D=.85$ ), indicating a high degree of content validity for the applied case profiles. In order to test the objectivity of the rating system, a random selection of 18 videotaped simulations was scored by two independent raters. Inter-rater reliabilities for each variable resulted in satisfactory intra-class-correlations (ICC; McGraw \& Wong, 1996) between ICC $=.76$ and ICC $=1.00$.

\subsection{Analyses}

Data analyses were performed using the software package SPSS Statistics Version 22. For all inferential statistics, the respective assumptions for the computed analyses were met. To examine the appropriateness of the counseling talk simulations to assess changes in prospective teachers' counseling competence due to specific interventions (hypothesis 1), we performed multivariate repeated measures MANOVAs with the within-subjects factor time (pretest, posttest) for the simulation and scenario test data of the experimental group 1. Subsequently, we compared the results received from the counseling talk simulations with the results received from the scenario test. To investigate the suitability of the counseling talk simulations as an effective intervention for the improvement of prospective teachers' counseling competence, knowledge, professional self-concept, and experience (hypothesis 2), we performed an additional multivariate repeated measures MANOVA for the experimental groups 1 and 2 with the between-subjects factor group (EG1, EG2) and the within-subjects factor time (pretest, posttest) on the basis of the paper-pencil data. 
Table 2. Excerpts of the rating system for the analysis of the counseling talk simulations

\begin{tabular}{|c|c|c|c|}
\hline $\begin{array}{l}\text { Dependent } \\
\text { Variable }\end{array}$ & Score & Criteria & Exemplary statements or questions \\
\hline \multirow[t]{3}{*}{ Paraphrasing } & 1 & Use of conversation techniques & \\
\hline & & $\begin{array}{l}\text { Paraphrasing (repeating in your own } \\
\text { words what the parent has said) at an } \\
\text { appropriate point in the talk }\end{array}$ & $\begin{array}{l}\text { "If I understand you correctly, you think..."; } \\
\text { "In other words..." }\end{array}$ \\
\hline & 2 & $\begin{array}{l}\text { Use of conversation techniques } \\
\text { Paraphrasing at at least two appropriate } \\
\text { points in the talk }\end{array}$ & $\begin{array}{l}\text { "If I understand you correctly, you think..."; } \\
\text { "In other words..." }\end{array}$ \\
\hline \multirow{5}{*}{$\begin{array}{l}\text { Search for } \\
\text { possible } \\
\text { causes }\end{array}$} & 1 & $\begin{array}{l}\text { Naming possible causes; asking about } \\
\text { possible causes }\end{array}$ & $\begin{array}{l}\text { "I think your child's grades have gone down } \\
\text { because he is no longer motivated."; }\end{array}$ \\
\hline & & & $\begin{array}{l}\text { "What do you think has caused your child's } \\
\text { grades to go down?" }\end{array}$ \\
\hline & 2 & $\begin{array}{l}\text { Detailed inquiries concerning learning } \\
\text { and homework situation }\end{array}$ & $\begin{array}{l}\text { "Does your child have his own desk at } \\
\text { home?”; }\end{array}$ \\
\hline & & & “When does your child do his homework?”; \\
\hline & & & $\begin{array}{l}\text { "Does your child make a learning plan when } \\
\text { he is studying for a test?" }\end{array}$ \\
\hline \multirow[t]{4}{*}{$\begin{array}{l}\text { Strategy } \\
\text { application }\end{array}$} & 1 & $\begin{array}{l}\text { Suggest an appropriate solution (e.g., } \\
\text { homework journal, learning plan, } \\
\text { checklists, learning contract, reward } \\
\text { system, mistake analysis, etc.) }\end{array}$ & $\begin{array}{l}\text { “I would suggest that your child keep a } \\
\text { homework journal in the next few weeks.”; } \\
\text { “It might help to make a weekly plan.”; } \\
\text { “With other students who had similar }\end{array}$ \\
\hline & & $\begin{array}{l}\text { + explanation of practical } \\
\text { implementation }\end{array}$ & $\begin{array}{l}\text { problems, I have had good experiences with } \\
\text { reward systems." }\end{array}$ \\
\hline & 2 & $\begin{array}{l}\text { Suggest several appropriate solutions } \\
\text { (e.g., homework journal, learning plan, } \\
\text { checklists, learning contract, reward } \\
\text { system, mistake analysis, etc.) }\end{array}$ & $\begin{array}{l}\text { “I would suggest that your child keep a } \\
\text { homework journal in the next few weeks.”; } \\
\text { “It might help to make a weekly plan.”; } \\
\text { “With other students who had similar }\end{array}$ \\
\hline & & $\begin{array}{l}\text { + explanation of practical } \\
\text { implementation }\end{array}$ & $\begin{array}{l}\text { problems, I have had good experiences with } \\
\text { reward systems." }\end{array}$ \\
\hline \multirow{8}{*}{$\begin{array}{l}\text { Cooperative } \\
\text { actions }\end{array}$} & 1 & Show understanding; & "I completely understand how you feel."; \\
\hline & & Emphasize willingness to cooperate; & “Together we will manage that.”; \\
\hline & & $\begin{array}{l}\text { Signal availability for future questions } \\
\text { and comments }\end{array}$ & $\begin{array}{l}\text { "If you have any questions, you can always } \\
\text { contact me." }\end{array}$ \\
\hline & 2 & Show understanding; & “I completely understand how you feel."; \\
\hline & & Emphasize willingness to cooperate; & “Together we will manage that.”; \\
\hline & & $\begin{array}{l}\text { Signal availability for future questions } \\
\text { and comments }\end{array}$ & $\begin{array}{l}\text { "If you have any questions, you can always } \\
\text { contact me." }\end{array}$ \\
\hline & & + & + \\
\hline & & $\begin{array}{l}\text { Actively include parent in problem } \\
\text { definition as well as search for causes } \\
\text { and solutions; offer support in } \\
\text { implementing solutions or take on task } \\
\text { yourself }\end{array}$ & $\begin{array}{l}\text { "Which of the possible solutions that I } \\
\text { mentioned do you think would work best with } \\
\text { your child?"; } \\
\text { "I'd be happy to fill out the weekly plan with } \\
\text { your child." }\end{array}$ \\
\hline
\end{tabular}




\section{Results}

3.1 Appropriateness of the Counseling Talk Simulations for the Assessment of Changes in Prospective Teachers' Counseling Competence due to Specific Interventions

The repeated measures MANOVAs for the experimental group 1 revealed a significant overall main effect of the within-subjects factor time (pretest, posttest) for the simulation data (Wilks' lambda $\Lambda=.246, F(4,21)=16.05, p$ $<.001, \eta^{2}=.75$ ) as well as the scenario test data (Wilks' lambda $\Lambda=.043, F(4,21)=116.28, p<.001, \eta^{2}=.96$ ). As hypothesized (hypothesis 1), we found significant positive main effects with large effect sizes (Cohen, 1988) measured by means of both instruments with regard to prospective teachers' overall counseling competence as well as the dimensions communication skills, diagnostic skills, and problem-solving skills. Against our hypothesis, analyses revealed different results concerning the coping skills dimension. Table 3 displays the comparison of the results of the repeated measures MANOVAs for the examination of intervention effects on the basis of the counseling talk simulation data and the scenario test data, including pretest and posttest means as well as standard deviations.

Table 3. Results of the multivariate repeated measures MANOVAs for the examination of intervention effects on the basis of the scenario test data and the counseling talk simulation data

\begin{tabular}{|c|c|c|c|c|c|c|c|c|}
\hline \multirow{3}{*}{ Dependent variables } & \multicolumn{4}{|c|}{ Scenario test } & \multicolumn{4}{|c|}{ Counseling talk simulations } \\
\hline & \multirow{2}{*}{$\begin{array}{c}\text { Pretest } \\
M(S D)\end{array}$} & \multirow{2}{*}{$\begin{array}{l}\text { Posttest } \\
M(S D)\end{array}$} & \multicolumn{2}{|c|}{ Main effect time } & \multirow{2}{*}{$\begin{array}{c}\text { Pretest } \\
M(S D)\end{array}$} & \multirow{2}{*}{$\begin{array}{c}\text { Posttest } \\
M(S D)\end{array}$} & \multicolumn{2}{|c|}{ Main effect time } \\
\hline & & & $\boldsymbol{F}$ & $\eta^{2}$ & & & $\boldsymbol{F}$ & $\eta^{2}$ \\
\hline Counseling competence $^{a}$ & $.83(.20)$ & $1.81(.16)$ & $396.42 * * *$ & .94 & $.99(.22)$ & $1.39(.18)$ & $52.96^{* * *}$ & .69 \\
\hline Communication skills ${ }^{a}$ & $.44(.21)$ & $1.81(.32)$ & $316.88 * * *$ & .93 & $.70(.26)$ & $1.10(.32)$ & $22.68 * * *$ & .49 \\
\hline Diagnostic skills ${ }^{a}$ & $1.42(.27)$ & $1.83(.19)$ & $29.23 * * *$ & .55 & $1.16(.37)$ & $1.58(.34)$ & $18.12 * * *$ & .43 \\
\hline Problem-solving skills ${ }^{a}$ & $.91(.29)$ & $1.84(.16)$ & $167.74 * * *$ & .88 & $1.05(.32)$ & $1.65(.27)$ & $61.71 * * *$ & .72 \\
\hline Coping skills ${ }^{\mathrm{a}}$ & $.54(.48)$ & $1.74(.29)$ & $157.09 * * *$ & .87 & $1.04(.43)$ & $1.22(.50)$ & 2.45 & .09 \\
\hline
\end{tabular}

\subsection{Appropriateness of the Counseling Talk Simulations as an Intervention}

The multivariate repeated measures MANOVA for the experimental groups 1 and 2 with the between-subjects factor group (EG1, EG2) and the within-subjects factor time (pretest, posttest) on the basis of the paper-pencil data resulted in a significant overall interaction effect for group * time (Wilks' lambda $\Lambda=.487, F(7,43)=6.46$, $p<.001, \eta^{2}=.513$ ). In accordance with our hypothesis (hypothesis 2 ), closer inspection revealed significant effects with large to medium effect sizes (Cohen, 1988) of participation in the counseling talk simulations on prospective teachers' overall counseling competence, the dimensions problem-solving skills and coping skills, as well as knowledge and professional self-concept. For the dimensions communication skills and diagnostic skills as well as counseling experience analyses did not reveal significant intervention effects. Pretest and posttest means, standard deviations, and results of the repeated measures MANOVA are displayed in Table 4. 
Table 4. Results of the multivariate repeated measures MANOVA for the examination of intervention effects of participation in the counseling talk simulations

\begin{tabular}{|c|c|c|c|c|c|c|}
\hline \multirow{2}{*}{ Dependent variables } & \multirow{2}{*}{\multicolumn{2}{|c|}{$\begin{array}{l}\text { Pretest } \\
M(S D)\end{array}$}} & \multirow{2}{*}{\multicolumn{2}{|c|}{$\begin{array}{c}\text { Posttest } \\
M(S D)\end{array}$}} & \multicolumn{2}{|c|}{ Interaction group * time } \\
\hline & & & & & $\boldsymbol{F}$ & $\eta^{2}$ \\
\hline & & & & & $14.11 * * *$ & \\
\hline EG1 & .86 & $(.19)$ & 1.81 & $(.15)$ & & \\
\hline EG2 & .87 & $(.15)$ & 1.58 & $(.25)$ & & \\
\hline Communication skills ${ }^{a}$ & & & & & $3.54 \#$ & .07 \\
\hline EG1 & .44 & $(.21)$ & 1.81 & $(.32)$ & & \\
\hline EG2 & .49 & $(.22)$ & 1.64 & $(.40)$ & & \\
\hline Diagnostic skills $^{\mathrm{a}}$ & & & & & 2.32 & .05 \\
\hline EG1 & 1.42 & $(.27)$ & 1.83 & $(.19)$ & & \\
\hline EG2 & 1.30 & $(.31)$ & 1.55 & $(.34)$ & & \\
\hline Problem-solving skills ${ }^{\mathrm{a}}$ & & & & & $6.76^{*}$ & .12 \\
\hline EG1 & .91 & $(.29)$ & 1.84 & $(.16)$ & & \\
\hline EG2 & 1.05 & $(.27)$ & 1.71 & $(.26)$ & & \\
\hline Coping skills $^{\mathrm{a}}$ & & & & & $6.79 *$ & .12 \\
\hline EG1 & .54 & $(.48)$ & 1.74 & $(.29)$ & & \\
\hline EG2 & .46 & $(.40)$ & 1.25 & $(.62)$ & & \\
\hline Knowledge $^{\mathrm{b}}$ & & & & & $24.65 * * *$ & .34 \\
\hline EG1 & 5.20 & (1.12) & 7.72 & $(.98)$ & & \\
\hline EG2 & 6.38 & $(1.02)$ & 7.19 & 1.13) & & \\
\hline Professional self-concept ${ }^{\mathrm{c}}$ & & & & & $6.65^{*}$ & .12 \\
\hline EG1 & 4.50 & $(.41)$ & 5.15 & $(.44)$ & & \\
\hline EG2 & 4.48 & $(.39)$ & 4.83 & $(.37)$ & & \\
\hline Experience $^{c}$ & & & & & 1.02 & .02 \\
\hline EG1 & 1.95 & $(.63)$ & 3.28 & $(.65)$ & & \\
\hline EG2 & 2.13 & $(.75)$ & 3.24 & $(.63)$ & & \\
\hline
\end{tabular}

Note. ${ }^{a}$ Range $0-2(0=$ min. parameter value; $2=\max$. parameter value $) .{ }^{b}$ Range $0-9(0=$ min. parameter value; $9=$ max. parameter value). Range 1-6 $(1=$ min. parameter value; $6=\max$. parameter value $) .{ }^{*} p<.05 . * * p$ $<.01 . * * *<.001$.

\section{Discussion}

The central purpose of the current study was to develop and validate a behavior-based instrument for the assessment and improvement of teachers' counseling competence involving counseling talk simulations with standardized parents.

The simulated parent-teacher talks turned out to be an appropriate instrument for the measurement of changes in prospective teachers' counseling competence due to specific interventions. This conclusion is drawn in view of the consistencies of the intervention effects of the training program measured by means of the counseling talk simulations and the already established scenario test for the assessment of teachers' counseling competence (Bruder, 2011; Gerich et al., 2015) for almost all examined variables. Here, following the approaches established by Dotger et al. $(2008,2010)$ and Wiesbeck et al. $(2013)$ proved to be expedient. The fact that the counseling talk simulations were developed on the basis of the four-dimensional model of teachers' counseling competence (Gerich et al., 2015) allows for the behavior-based assessment of teachers' counseling competence on an overall level as well as subdivided into the single dimensions. This, in turn, enables the differential assessment of individuals' and groups' specific needs, the creation of individual competence profiles, and the subsequent design of precisely tailored interventions for specific target groups. Moreover, as the results of the current study revealed, the counseling talk simulations can be used for the systematic evaluation of the according interventions.

The results of the current study also highlight the effectiveness of the counseling talk simulations as an intervention within the framework of teacher education programs on counseling. The exposure to realistic and 
complex application situations allowed prospective teachers to practice and refine their professional counseling competences, acquire professional knowledge of counseling and learning strategies, and develop a professional self-concept as a counselor. Moreover, by means of the simulated parent-teacher talks, prospective teachers were enabled to engage in and address common problems of the professional counseling practice while they were still under the care and guidance of the teacher training course. Consequently, the outlined simulation approach might serve as an inspiration for the design of future teacher education programs on parent or student counseling. In this context, the video recording of the simulated counseling talks could be used for the subsequent joint analysis of participants' counseling behavior, in order to provide prospective teachers the opportunity to conduct detailed self-evaluations and reflect on multiple aspects of their professional performance, which is considered to be a key element in the context of integrating theoretical knowledge and practical skills (Ericsson, Krampe, \& Tesch-Römer, 1993; Parsons \& Stephenson, 2005). Particularly in research on teacher education, the importance of reflection following active learning for the long-term development of practical competences is consistently highlighted (Admiraal et al., 2011; Watts \& Lawson, 2009). As reflections induced by watching video recordings of one's own professional practice have been shown to be beneficial in the context of acquiring professional competences in teacher education programs worldwide (Bryan \& Recesso, 2006; Rich, Recesso, Allexsaht-Snider, \& Hannafin, 2007), even the analysis of the videotaped simulated counseling talks might support prospective teachers in developing their professional counseling competences. Here, the focus of the self-reflections should be on the identification of potential differences between participants' beliefs regarding good counseling and their actual practices (Bryan \& Recesso, 2006; Rich \& Hannafin, 2008) as well as the recognition of individual strengths and weaknesses of their counseling behaviors (Rich et al., 2007; Wu \& Kao, 2008). This might lead to the setting of specific individual learning goals, a heightened motivation to improve one's own counseling competence, and an increased personal responsibility for one's own learning processes (Andrade \& Valtcheva, 2009). Finally, this might result in a long-term increase in participants' counseling competence (Rich et al., 2007; Taras, 2010) and professional self-concept (Beijaard, Meijer, \& Verloop, 2004).

In addition to the one-time recording and watching of a simulated parent-teacher talk for the determination of prospective teachers' current counseling competence, the viewing of videotaped simulations recorded at different times could provide participants the opportunity to observe their individual progress over the course of the specific teacher training program (Tripp \& Rich, 2012). In addition to individually watching and reflecting on the videotapes, prospective teachers should be provided the opportunity to collaboratively watch and discuss their videos with peers in a learning group (Harford, MacRuairc, \& McCartan, 2010), as evidence-based feedback and suggestions for improvement from a discussion group might also encourage efforts for continuing professional development (Tripp \& Rich, 2012). In this connection, prospective teachers should be given feedback not only by peers but also by educators. In this case, the feedback should provide prospective teachers with information on their individual strengths and areas for improvement as well as encourage reflections on their counseling behavior in the past simulation and, on that basis, support the preparation for the next simulation. However, not only the individual participant but also the entire learning group could benefit from the collaborative analysis of the simulation videos, as the viewing of video cases represents a powerful instructional tool in developing teacher competences (Brophy, 2004) and professional identities (Maclean \& White, 2007). In terms of model learning, prospective teachers can learn about effective professional practice by observing the successes and struggles of others taking part in the simulations and the subsequent self-evaluation of their own practice (Masingila \& Doerr, 2002). This has been demonstrated for skills relevant to communicating with parents, in particular (Walker \& Dotger, 2012). Activities involving video analysis, moreover, have the potential to meaningfully guide the acquisition, activation, and application of prospective teachers' knowledge (Seago, 2004) and help them to relate their university learning to their later professional practice (Marsh \& Mitchell, 2014). Furthermore, the introduction of video models contributes to prospective teachers' understanding of the expectations regarding their later professional performance (Baecher, Kung, Jewkes, \& Rosalia, 2013).

\subsection{Limitations and Outlook}

Although the current study yielded important new findings for the assessment and improvement of prospective teachers' counseling competence, the results must be viewed in light of several limitations that may be addressed in future studies.

Firstly, it has to be mentioned that the application of the counseling talk simulations as an assessment instrument as well as an intervention requires an extensive amount of resources. Consequently, for the assessment of teachers' counseling competence in the context of studies with large sample sizes, the utilized scenario test (Bruder, 2011; Gerich et al., 2015) still appears to be the method of choice, as it allows for the context specific and standardized measurement of teachers' counseling competence in a highly economical manner (cf., Hedlund 
et al., 2006). Nevertheless, the counseling talk simulations turned out to be appropriate within the framework of teacher education programs on counseling with smaller numbers of participants such as in the current study. However, as our results are based on a relatively small sample, they may not necessarily be generalizable to the entire population of prospective teachers. Therefore, additional studies should focus on the replication of the outlined findings on the basis of a larger set of participants.

Another limitation concerns the inconsistent assessments determined by means of the simulations and the scenario test regarding the intervention effects of the training program on prospective teachers' coping skills. A possible reason for this may consists in certain weaknesses of the applied rating system for the analysis of participants' coping skills within the simulations. On this account, future research should focus on the continuing optimization of the rating system, particularly regarding the competence dimension coping skills. However, the divergent results delivered by the two instruments may also be caused by the different requirements of the simulation context and the scenario test completion context. Within the simulations, participants must react immediately to the simulated parent's questions and statements, whereas they have the possibility to carefully consider their responses while completing the paper-pencil scenario test. This difference might become particularly apparent when participants are challenged to cope with difficult situations in the course of the counseling talk. In this context, consideration could also be given to the differing extent of evoking socially desirable behavior. It is conceivable that the social observation context and the direct interaction with a conversational partner within the simulations lead to more socially desirable responses (e.g., refrain from criticism) than the completion context of the scenario test. Consequently, additional possible reasons for the divergent results of the two instruments concerning the dimension coping skills are specific weaknesses of the scenario test, namely an insufficient suitability for the representation of difficult situations in a parent-teacher talk. Therefore, future research should also focus on the further validation of the scenario test regarding the assessment of participants' coping skills. However, it should be noted that even the counseling talk simulations have a certain laboratory character. Although the implementation of simulated parent-teacher talks allows for the observation of actual behavior in concrete, realistic application contexts, the simulations are still based on role-playing with standardized parents. Thus, with special regard to validation in the field, data collected by means of the counseling talk simulations may be compared with video recordings of real parent-teacher talks in teachers' professional routines.

An additional limitation of the current study concerns the missing intervention effects of participation in the counseling talk simulations on the development of prospective teachers' communication skills, diagnostic skills, and experience. A possible explanation may be that prospective teachers participated in the simulations only on two occasions. In this context, the beneficial effects of providing participants more frequent and repeated opportunities to practice their professional counseling competences and, consequently, gain essential experience should be investigated in subsequent studies. As already mentioned above, continuing research might also address the examination of additional beneficial effects of standardized individual feedback concerning prospective teachers' counseling performance during the counseling talk simulations on their competence improvement.

Within the framework of the continuing improvement of the counseling talk simulations, continued efforts should also focus on the development of additional case scenarios with varying levels of complexity and various types of students' and parents' demands. This will allow for the coordination of the selected case scenarios' degree of difficulty with participants' individual competence level as well as provide prospective teachers the opportunity to demonstrate and develop their counseling competences in increasingly demanding counseling situations.

Finally, the simulated parent-teacher talks and subsequent feedback by peers and teacher educators could also be implemented in the continuing education of practicing teachers. As the videotaping of real-life parent-teacher talks is permitted by parents only in a very small minority of cases, the videotaping of the simulations could provide in-service teachers the opportunity to discuss and reflect on their professional performance in parent-teacher talks even in later stages of their professional career.

\section{Acknowledgement}

The preparation of this paper was supported by grants SCHM 1538/5-3 from the German Research Foundation (DFG) in the Priority Program "Competence Models for Assessing Individual Learning Outcomes and Evaluating Educational Processes" (SPP 1293). 


\section{References}

Admiraal, W., Hoeksma, M., Van de Kamp, M.-T., \& Van Duin, G. (2011). Assessment of teacher competence using video portfolios. Reliability, construct validity, and consequential validity. Teaching and Teacher Education, 27, 1019-1028. http://dx.doi.org/10.1016/j.tate.2011.04.002

Andrade, H., \& Valtcheva, A. (2009). Promoting learning and achievement through self-assessment. Theory into Practice, 48, 12-19. http://dx.doi.org/10.1080/00405840802577544

Baecher, L., Kung, S.-C., Jewkes, A. M., \& Rosalia, C. (2013). The role of video for self-evaluation in early field experiences. Teaching and Teacher Education, 36, 189-197. http://dx.doi.org/10.1016/j.tate.2013.08.001

Baumert, J., \& Kunter, M. (2006). Stichwort: Professionelle Kompetenz von Lehrkräften. Zeitschrift für Erziehungswissenschaft, 9, 469-520. http://dx.doi.org/10.1007/s 11618-006-0165-2

Beijaard, D., Meijer, P. C., \& Verloop, N. (2004). Reconsidering research on teachers' professional identity. Teaching and Teacher Education, 20, 107-128. http://dx.doi.org/10.1016/j.tate.2003.07.001

Brophy, J. (2004). Using video in teacher education. Oxford, UK: Elsevier.

Bruder, S. (2011). Lernberatung in der Schule. Ein zentraler Bereich professionellen Lehrerhandelns [Counseling in terms of learning strategies in school. A central aspect of teachers' professional action] (Doctoral dissertation). Technische Universität Darmstadt, Germany. Retrieved from http://tuprints.ulb.tu-darmstadt.de/2432/

Bruder, S., Keller, S., Klug, J., \& Schmitz, B. (2011). Ein Vergleich situativer Methoden zur Erfassung der Beratungskompetenz von Lehrkräften [Comparison of situational methods for assessing teachers' counseling competence]. Unterrichtswissenschaft, 39, 123-137.

Bryan, L. A., \& Recesso, A. (2006). Promoting reflection with a web-based video analysis tool. Journal of Computing in Teacher Education, 23, 31-39. http://dx.doi.org/10.1080/10402454.2006.10784557

Carmines, E. G., \& Zeller, R. A. (1991). Reliability and validity assessment. Newbury Park, CA: SAGE.

Cohen, J. (1988). Statistical power analysis for the behavioral sciences. Hillsdale, NJ: Erlbaum.

Constantine, M. G., \& Ladany, N. (2000). Self-report multicultural counseling competence scales. Their relation to social desirability attitudes and multicultural case conceptualization ability. Journal of Counseling Psychology, 47, 155-164. http://dx.doi.org/10.1037/0022-0167.47.2.155

Cox, D. D. (2005). Evidence-based interventions using home-school collaboration. School Psychology Quarterly, 20, 473-497. http://dx.doi.org/10.1521/scpq.2005.20.4.473

Dotger, B. H., Dotger, S. C., \& Maher, M. J. (2010). From medicine to teaching. The evolution of the Simulated $\begin{array}{lllll}\text { Interaction } \quad \text { Model. Innovative Higher Education, } & \text { 35, }\end{array}$ http://dx.doi.org/10.1007/s10755-009-9128-x

Dotger, B. H., Harris, S. H., \& Hansel, A. (2008). Emerging authenticity. The crafting of simulated parent-teacher candidate conferences. Teaching Education, 19, 335-347. http://dx.doi.org/10.1080/ 10476210802438324

Ericsson, K. A., Krampe, R. T., \& Tesch-Römer, C. (1993). The role of deliberate practice in the acquisition of expert performance. Psychological Review, 100, 363-406. http://dx.doi.org/10.1037/0033-295X.100.3.363

Fan, X., \& Chen, M. (2001). Parental involvement and students' academic achievement. A meta-analysis. Educational Psychology Review, 13, 1-22. http://dx.doi.org/10.1023/A:1009048817385

Gallagher, M. S., \& Hargie, O. D. W. (1989). An investigation into the validity of role play as procedure for counsellor skill assessment. British Journal of Guidance and Counselling, 17, 155-165. http://dx.doi.org/10.1080/03069888908258050

Gartmeier, M., Bauer, J., Fischer, M. R., Karsten, G., \& Prenzel, M. (2011). Modellierung und Assessment professioneller Gesprächsführungskompetenz von Lehrpersonen im Lehrer-Elterngespräch [Modeling and assessing teachers" professional communicative competence in parent-teacher conversation]. In $\mathrm{O}$. Zlatkin-Troitschanskaia (Ed.), Stationen Empirischer Bildungsforschung. Traditionslinien und Perspektiven [Stages of empirical educational research. Lines of tradition and perspectives] (pp. 412-426). Wiesbaden, Germany: VS Verlag für Sozialwissenschaften. http://dx.doi.org/10.1007/978-3-531-94025-0_29 
Gerich, M., Bruder, S., Hertel, S., Trittel, M., \& Schmitz, B. (2015). What skills and abilities are essential for counseling on learning difficulties and learning strategies? Modeling teachers' counseling competence in parent-teacher talks measured by means of a scenario test. Zeitschrift für Entwicklungspsychologie und Pädagogische Psychologie, 47, 62-71. http://dx.doi.org/10.1026/0049-8637/a000127

Gerich, M., Trittel, M., \& Schmitz, B. (under review). Improving prospective teachers' counseling competence in parent-teacher talks. Effects of training and feedback. Journal of Educational and Psychological Consultation.

Grossman, P. (2005). Research on pedagogical approaches in teacher education. In M. Cochran-Smith, \& K. M. Zeichner (Eds.), Studying teacher education. The report of the AERA panel on research in teacher education (pp. 425-476). Mahwah, NJ: Erlbaum.

Guli, L. A. (2005). Evidence-based parent consultation with school-related outcomes. School Psychology Quarterly, 20, 455-472. http://dx.doi.org/10.1521/scpq.2005.20.4.455

Harford, J., MacRuairc, G., \& McCartan, D. (2010). "Lights, camera, reflection". Using peer video to promote reflective dialogue among student teachers. Teacher Development. An international journal of teachers' professional development, 14, 57-68. http://dx.doi.org/10.1080/13664531003696592

Hedlund, J., Witt, J. M., Nebel, K. L., Ashford, S. J., \& Sternberg, R. (2006). Assessing practical intelligence in business school admissions. A supplement to the graduate management admission test. Learning and Individual Differences, 16, 101-127. http://dx.doi.org/10.1016/j.lindif.2005.07.005

Henderson, A. T., \& Mapp, K. L. (2002). A new wave of evidence. The impact of school, family, and community connections on student achievement. Austin, TX: Southwest Educational Development Laboratory.

Hertel, S. (2009). Beratungskompetenz von Lehrern. Kompetenzdiagnostik, Kompetenzförderung, Kompetenzmodellierung [Teachers' counseling competence. Diagnostic, advancement, modeling]. Münster, Germany: Waxmann.

Hill, N. E., \& Tyson, D. F. (2009). Parental involvement in middle school. A meta-analytic assessment of the strategies that promote achievement. Developmental Psychology, 45, 740-763. http://dx.doi.org/10.1037/ a0015362

Hoover-Dempsey, K. V., Walker, J. M. T., Jones, K. P., \& Reed, R. P. (2002). Teachers Involving Parents (TIP). Results of an in-service teacher education program for enhancing parental involvement. Teaching and Teacher Education, 18, 843-867. http://dx.doi.org/10.1016/S0742-051X(02)00047-1

Kane, M. T. (1992). The Assessment of Professional Competence. Evaluation \& The Health Professions, 15, 163-182. http://dx.doi.org/10.1177/016327879201500203

Klug, J., Bruder, S., Kelava, A., Spiel, C., \& Schmitz, B. (2013). Diagnostic competence of teachers. A process model that accounts for diagnosing learning behavior tested by means of a case scenario. Teaching and Teacher Education, 30, 38-46. http://dx.doi.org/10.1016/j.tate.2012.10.004

Maclean, R., \& White, S. (2007). Video reflection and the formation of teacher identity in a team of pre-service and experienced teachers. Reflective Practice. International and Multidisciplinary Perspectives, 8, 47-60. http://dx.doi.org/10.1080/14623940601138949

Marsh, B., \& Mitchell, N. (2014). The role of video in teacher professional development. Teacher Development. An international journal of teachers' professional development, 18, 403-417. http://dx.doi.org/10.1080/ 13664530.2014 .938106

Masingila, J. O., \& Doerr, H. M. (2002). Understanding pre-service teachers' emerging practices through their analyses of a multimedia case study of practice. Journal of Mathematics Teacher Education, 5, 235-263. http://dx.doi.org/10.1023/A:1019847825912

McDaniel, M. S., Morgeson, F. P., Finnegan, E. B., Campion, M. A., \& Braverman, E. P. (2001). Use of situational judgment tests to predict job performance. A clarification of the literature. Journal of Applied Psychology, 80, 730-740. http://dx.doi.org/10.1037/0021-9010.86.4.730

McGraw, K. O., \& Wong, S. P. (1996). Forming inferences about some intra-class correlation coefficients. Psychological Methods, 1, 30-46. http://dx.doi.org/10.1037/1082-989X.1.1.30

McLeod, J. (2003). An introduction to counselling. Buckingham, UK: Open University Press. 
National Commission on Teaching and America's Future. (1997). Doing what matters most. Investing in quality teaching. Report of the National Commission on Teaching \& America's Future. Woodbridge, VA: National Commission on Teaching and America's Future.

Parsons, M., \& Stephenson, M. (2005). Developing reflective practice in student teachers. Collaboration and critical partnerships. Teachers and Teaching. Theory and Practice, 11, 95-116. http://dx.doi.org/10.1080/ 1354060042000337110

Pomerantz, E. M., Moorman, E. A., \& Litwack, S. D. (2007). The how, whom, and why of parents' involvement in children's academic lives. More is not always better. Review of Educational Research, 77, 373-410. http://dx.doi.org/10.3102/003465430305567

Ramsey, M. C., \& Reynolds, C. R. (2000). Development of a Scientific Test. A Practical Guide. In G. Goldstein, \& M. Hersen (Eds.), Handbook of psychological assessment (pp. 21-42). Oxford, UK: Elsevier Science. http://dx.doi.org/10.1016/B978-008043645-6/50080-X

Rich, P. J., \& Hannafin, M. J. (2008). Capturing and assessing evidence of student teacher inquiry. A case study. Teaching and Teacher Education, 24, 1426-1440. http://dx.doi.org/10.1016/j.tate.2007.11.016

Rich, P. J., Recesso, A., Allexsaht-Snider, M., \& Hannafin, M. J. (2007). The use of video-based evidence to analyze, act on, and adapt preservice teacher practice. Chicago, IL: American Educational Research Association.

Seago, N. (2004). Using video as an object of inquiry mathematics teaching and learning. In J. Brophy (Ed.), Using video in teacher education (pp. 259-285). Oxford, UK: Elsevier.

Sheridan, S. M., Kratochwill, T. R., \& Bergan, J. R. (1996). Conjoint behavioral consultation. A procedural manual. New York, NY: Plenum Press. http://dx.doi.org/10.1007/978-1-4757-2512-4

Spencer, L. M., \& Spencer, S. M. (1993). Competence at work. Models for superior performance. New York, NY: Wiley.

Standing Conference of the Ministers of Education and Cultural Affairs of the States in the Federal Republic of Germany. (2004). Standards für die Lehrerbildung: Bildungswissenschaften. Beschluss der Kultusministerkonferenz vom 16.12.2004 [Standards for teacher education. Educational sciences. Resolution of 16.12.2004]. Retrieved from http://www.kmk.org/fileadmin/veroeffentlichungen beschluesse/2004/2004_12_16-Standards-Lehrerbildung.pdf

Taras, M. (2010). Student self-assessment. Processes and consequences. Teaching in Higher Education, 15, 199-209. http://dx.doi.org/10.1080/13562511003620027

Tripp, T. R., \& Rich, P. J. (2012). The influence of video analysis on the process of teacher change. Teaching and Teacher Education, 28, 728-739. http://dx.doi.org/10.1016/j.tate.2012.01.011

Valli, L., \& Rennert-Ariev, P. L. (2000). Identifying consensus in teacher education reform documents. A proposed framework and action implications. Journal of Teacher Education, 51, 5-17. http://dx.doi.org/ $10.1177 / 002248710005100102$

Walker, J. M. T., \& Dotger, B. H. (2012). Because wisdom can't be told. Using comparison of simulated parent-teacher conferences to assess teacher candidates' readiness for family-school partnership. Journal of Teacher Education, 63, 62-75. http://dx.doi.org/10.1177/0022487111419300

Watts, M., \& Lawson, M. (2009). Using a meta-analysis activity to make critical reflection explicit in teacher education. Teaching and Teacher Education, 25, 609-616. http://dx.doi.org/10.1016/j.tate.2008.11.019

Whiston, S. C., Tai, W. L., Rahardja, D., \& Eder, K. (2011). School counseling outcome. A meta-analytic examination of interventions. Journal of Counseling and Development, 89, 37-55. http://dx.doi.org/10.1002/ j.1556-6678.2011.tb00059.x

Wiesbeck, A., Bauer, J., Gartmeier, M., \& Prenzel, M. (2013). Förderung und Assessment von Gesprächsführungskompetenz. Interdisziplinäre Perspektiven aus Medizin und Lehramt. Simulierte Gespräche als Methode zur Messung der Gesprächsführungskompetenz [Promotion and assessment of communicative competence. Interdisciplinary perspectives from medical and teaching profession. Simulated conversations as a method for measuring communicative competence]. Paper presented at the 1 . Meeting of Society for Empirical Education Research (GEBF) in Kiel, Germany. 
Wu, C., \& Kao, H. (2008). Streaming video in peer assessment to support training pre-service teachers. Educational Technology \& Society, 11, 45-55.

\section{Copyrights}

Copyright for this article is retained by the author(s), with first publication rights granted to the journal.

This is an open-access article distributed under the terms and conditions of the Creative Commons Attribution license (http://creativecommons.org/licenses/by/3.0/). 